ISSN 1112-9867

\title{
FITNESS PROFESSIONALS' KNOWLEDGE AND PERCEPTIONS ON HYDRATION AND FLUID INTAKE: A PRELIMINARY STUDY
}

\author{
N. Jusoh ${ }^{1, *}$ and S. M. Shirreffs ${ }^{2}$ \\ ${ }^{1}$ Faculty of Sport Sciences and Coaching, Universiti Pendidikan Sultan Idris, Tanjung Malim, \\ Perak, Malaysia \\ ${ }^{2}$ School of Sport, Exercise and Health Sciences, Loughborough University, Leics. LE11 3TU, \\ United Kingdom
}

Published online: 10 November 2017

\begin{abstract}
This descriptive study examined the extent of hydration knowledge and fluid intake pattern in people who work within fitness industry. Fourty fitness professionals were asked to complete a questionnaire about their perspectives on hydration, thirst and fluid intake pattern. Water was the most preferred drink before (75.0\%), during (72.5\%) and after exercise $(60.0 \%)$ as well as generally during the day (75.0\%). Most participants rated plain tap water and plain bottled mineral water as excellent sources of water for human body, whereas colas or lemonade and chocolate drinks were rated as a poor source of water. To conclude, the fitness professionals generally demonstrated substantial knowledge about the timing and benefits of fluid replacement, hydration status monitoring and the health consequences of water consumption, but lack understanding on the type of beverages that adequately hydrate the body.
\end{abstract}

Keywords: thirst; fluid balance; fluid intake; personal trainers; knowledge.

Author Correspondence, e-mail: normah@fsskj.upsi.edu.my

doi: $\underline{\text { http://dx.doi.org/10.4314/jfas.v9i6s.75 }}$ 


\section{INTRODUCTION}

Simple observation of the general population suggests that drinking practices have changed significantly over the past 10 to 20 years. Nowadays, it is common to see people carry a water bottle with them during the day either in sedentary individuals or in people who perform regular physical activity. In fact, there is a substantial amount of information regarding hydration available both in printed or online format, suggesting that people should either drink sufficiently for the benefits of health or exercise performance or both.

However, not all information regarding hydration strategies are backed up with scientific evidence, and therefore could be misleading. Valtin [1] in his review about the origin of the "drinking at least eight glass of water a day" recommendations for healthy individuals performing at least mild exercise concludes that such a recommendation has no support from scientific evidence.

Another common belief, which has been taken literally by the public, is that consuming caffeinated beverages is dehydrating and may compromise hydration status that was based on earlier evidence $[2,3]$. However, these views have been challenged by recent evidence that caffeine-containing beverages do not affect fluid balance if consumed in amounts normally found in standard servings of coffee, tea and soft drinks [4] and that the caffeinated beverages hydrate the body as good as plain water [5, 6]. A study by Grandjean et al. [5] on the effect of two regimes, one with plain water and another without plain water on the hydration status showed the similar results. In that study, twenty-seven healthy sedentary males undertook two trials with two diet regimes, one included plain water and caffeinated drinks as part of the beverages and another trial provided caffeinated drinks without plain water, while diet, physical activity and environment were controlled. They found no significant differences $(\mathrm{P}>0.05)$ between trials for hydration status markers such as body weight changes, urine osmolality and urine specific gravity, and hence concluded that caffeinated beverages also support hydration. Similarly, a study conducted by Ruxton and Hart [6] on 21 healthy male adults by comparing the intake of black tea and boiled water revealed that there were no significant differences in all urine and blood variables related to hydration status.

To deal with this kind of misinformation, sound knowledge is crucial so that the correct hydration practice could be instilled. To date, much information about hydration knowledge is 
from studies on athletes $[7,8,9]$, but such information is lacking in free-living individuals and recreationally active people. In general, the findings in these studies conclude that these populations generally exhibited poor knowledge and attitude towards hydration and needed to be educated for proper fluid replacement and hydration. To demonstrate, Nichols and colleagues [8] investigated the knowledge, attitudes and behaviours regarding hydration and fluid intake in 139 collegiate athletes and reported that only $5.8 \%$ achieved a perfect score of $100 \%$ for 17 items of hydration knowledge questions. About one-third (33.1\%) of athletes gave a wrong answer for 14 out of 17 questions.

In addition, the athletes were knowledgeable about general hydration such as the importance of consuming fluid during and after training and competition, but lacked understanding with regard to an appropriate use of sports drinks. Another study by Felder et al. [7] on nutritional practices of 10 elite female surfers during training and competition showed that only $50 \%$ of the athletes consumed sport drink during competition and 40\% drank alcohol before competing on the competition day. The results suggest that the athletes practised the behaviour that could lead to dehydration and consequently might affect their performance.

The athletes become the target population for scientific study probably because the significant role of proper hydration in maintaining sports performance. Nevertheless, hydration knowledge and habits among general populations who are sedentary or recreationally active also need attention because proper hydration definitely helps to maintain general health on day-to-day basis $[10,11]$. Thus, this descriptive study was undertaken to gain an insight into hydration knowledge, opinions and fluid intake pattern in individuals who work within the fitness industry.

\section{METHODS}

\subsection{Participants}

The participants were recruited among the fitness professionals in Loughborough. After being given verbal and written information about the study, 40 people agreed to participate, giving

their written informed consent. The study protocol was approved by the Loughborough University Ethical Advisory Committee (R08-P46). 


\subsection{Instrument and Data Analysis}

In this descriptive study, the participants were asked to complete a questionnaire which consisted of two parts. Part A contained 6 questions on demographic information and Part B contained 10 questions to find out about their perspectives on hydration and fluid consumption. The items asked were combinations of open-ended and closed-ended type questionnaire. Statements for closed-ended question were either "yes" or "no". For a 5-point Likert scale question, the responses range from 1 (poor) to 5 (excellent). Responses for open-ended questions were classified into different main themes such as "hydration", "performance" and so forth. Similar responses for each question then were grouped together under the same themes and transferred into nominal scale for statistical analysis. For instance, answers such as "to maintain performance" and "to ensure good performance" were placed under "performance" theme and given a nominal code to calculate the statistics. This questionnaire took approximately 15-20 min to complete.

Before administering to the participants, the questionnaires were assessed for content validity by graduate students and lecturers of sport and exercise sciences at Loughborough University. The pilot test was conducted using 10 participants at Loughborough University. The internal reliability for the questionnaires was 0.74 as calculated using Cronbach alpha (SPSS 20.0). Hence, the value obtained in the present study suggests that the questionnaire had high internal reliability.

\subsection{Statistical analysis}

All data sets were tested for normal distribution using a Kolomogorov-Smirnov test. Parametric data are reported as mean $\pm \mathrm{SD}$. Responses to the open-ended questionnaires were treated as non-parametric data and the results were expressed as frequency, percentages and median (range). Data analysis was conducted using the Statistical Program for Social Sciences (SPSS) version 20.0.

\section{RESULTS AND DISCUSSION}

\subsection{Characteristics of the participants}

Twenty-three males and 17 females participated in this study. They had a mean age of $35 \pm 10$ years, and self-reported height and body mass of $1.72 \pm 0.10 \mathrm{~m}$ and $73 \pm 13 \mathrm{~kg}$, respectively. 
A total of 27 out of $40(67.5 \%)$ participants were working full time as personal trainers and fitness instructors. The remainder were part-time fitness instructors. In terms of the types of weekly exercise undertaken by the participants, strength training (31.2\%) was performed the most by the participants, followed by cardio session $(14.5 \%)$ and combinations of other activities (54.3\%) such as body balance, body combat, aquafit and teaching exercise classes.

\subsection{Perception on hydration and fluid intake pattern}

The participants were asked whether in their opinion they should drink before, during and after exercise with three options of "always", "sometimes" and "never". Eighty percent of participants stated that they should always drink before exercising. Likewise, $78.0 \%$ and 90.0\% participants chose the option should "always" drink during and after exercise, respectively. Meanwhile, only the respective $20.0 \%, 22.0 \%$ and $10.0 \%$ of the participants answered that they should "sometimes" drink before, during and after exercise. None of the participants chose the option "never" for these questions.

Table 1 presents the reasons given by the participants as to why they should drink before, during and after exercising. The reason "to stay hydrated" was given by most of the participants as to why they should drink before and during exercise $(40.0 \%$ and $67.5 \%$ respectively), and $62.5 \%$ of the participants answered "to replace fluid loss or recovery" as the reason for why they should drink after exercise.

Responses to the question on the best drink for the human body for before, during and after exercise as well as in general during the day are shown in Table 2. For all occasions, most of the participants believed that water is the best drink for human body $(85.0 \%$ for before exercise, $62.5 \%$ for during exercise, $50.0 \%$ for after exercise and $95.0 \%$ for general during the day).

The rationales for their opinion on the best drink for human body varied. The reason "to stay hydrated" was given by the majority of the participants for before $(50.0 \%)$ and during $(50.0 \%)$ exercise as well as in general during the day $(55.0 \%)$, whereas the reason "to replace fluid, energy and salt loss or recovery" was cited by the majority of the participants as regard to why they think their chosen drink is the best for human body after exercise $(52.5 \%)$.

In response to the question asking the participants to indicate their preferred drink, water tops the list for before exercise $(75.0 \%)$, during exercise $(72.5 \%)$ and after exercise $(57.5 \%)$ as 
well as generally during the day (75.0\%) (Table 3).

Table 1. Reasons for why the participants should drink before, during and after exercising

\begin{tabular}{|c|c|c|c|c|c|c|}
\hline \multirow[t]{2}{*}{ Reasons } & \multicolumn{2}{|c|}{$\begin{array}{c}\text { Before } \\
\text { exercise }\end{array}$} & \multicolumn{2}{|c|}{$\begin{array}{l}\text { During } \\
\text { exercise }\end{array}$} & \multicolumn{2}{|c|}{ After exercise } \\
\hline & $\mathbf{n}$ & $\%$ & $\mathbf{n}$ & $\%$ & $\mathbf{n}$ & $\%$ \\
\hline 1. To stay hydrated & 16 & 40.0 & 27 & 67.5 & 9 & 22.5 \\
\hline 2. To ensure optimum performance & 8 & 20.0 & 5 & 12.5 & 1 & 2.5 \\
\hline 3. Don't know & 6 & 15.0 & 5 & 12.5 & 5 & 12.5 \\
\hline 4. Pre hydration & 6 & 15.0 & na & na & na & na \\
\hline 5. If feel thirsty & 2 & 5.0 & na & na & na & na \\
\hline 6. To replace fluid loss/recovery & 2 & 5.0 & 3 & 7.5 & 25 & 62.5 \\
\hline
\end{tabular}

*na denotes not applied

When asked whether they were aware about their hydration status, $80.0 \%$ of the participants responded "yes", meanwhile $20.0 \%$ of them said they were not aware how hydrated they were at the moment they answered the questionnaire. For those who said they were aware of their hydration status, they were asked to list how they knew about it. "Watching urine colour" tops the list of responses given by the participants which was $32.6 \%$, followed by "I know how much I drink" (30.2\%), "feel thirsty" (14\%), "feel OK" (11.6\%), "having headache" (4.7\%) and "dry mouth", "enough saliva" and "energetic" which had a response of $2.3 \%$ respectively. The participants were also asked to report the volume of different type of beverages consumed in an average day. They stated the amount of drink in different units such as litre, millilitre, pint, glasses, and so forth, which were converted and standardised in litres. The results showed that plain tap water accounts for the highest volume reported to be consumed by the participants that was about $1.5 \pm 1.2 \mathrm{~L}$ per day, followed by plain bottled mineral water $(0.5 \pm 0.9 \mathrm{~L}$ per day) and other drinks such as tea $(0.4 \pm 0.5 \mathrm{~L}$ per day $)$, milk $(0.2 \pm 0.4 \mathrm{~L}$ per day), coffee (0.2 $\pm 0.3 \mathrm{~L}$ per day) and cola $(0.1 \pm 0.2 \mathrm{~L}$ per day). 
Table 2. Participants' opinion on the best drink for human body for before, during and after exercise and in general during the day $(\mathrm{n}=40)$.

\begin{tabular}{|c|c|c|c|c|c|c|c|c|}
\hline \multirow[t]{2}{*}{ Types of drink } & \multicolumn{2}{|c|}{$\begin{array}{l}\text { Before } \\
\text { exercise }\end{array}$} & \multicolumn{2}{|c|}{ During exercise } & \multicolumn{2}{|c|}{ After exercise } & \multicolumn{2}{|c|}{$\begin{array}{c}\text { General during } \\
\text { the day }\end{array}$} \\
\hline & $\mathbf{n}$ & $\%$ & $\mathbf{n}$ & $\%$ & $\mathbf{n}$ & $\%$ & $\mathbf{n}$ & $\%$ \\
\hline Water & 34 & 85.0 & 25 & 62.5 & 20 & 50.0 & 38 & 95.0 \\
\hline Sports drink & 1 & 2.5 & 11 & 27.5 & 12 & 30.0 & na & na \\
\hline CHO-protein mix & 1 & 2.5 & na & na & 1 & 2.5 & na & na \\
\hline Tea/ coffee & 1 & 2.5 & na & na & na & na & na & na \\
\hline Squash/cordial & 1 & 2.5 & na & na & na & na & 1 & 2.5 \\
\hline Water and fruit juice & 2 & 5.0 & 1 & 2.5 & 1 & 2.5 & 1 & 2.5 \\
\hline Water with $\mathrm{CHO}$ & na & na & na & na & 2 & 5.0 & na & na \\
\hline Flavoured water & na & na & 2 & 5.0 & 1 & 2.5 & na & na \\
\hline $\begin{array}{l}\text { Water with added } \\
\text { salt }\end{array}$ & na & na & 1 & 2.5 & 1 & 2.5 & na & na \\
\hline Fruit juice & na & na & na & na & 1 & 2.5 & na & na \\
\hline $\begin{array}{l}\text { Meal replacement } \\
\text { drink }\end{array}$ & na & na & na & na & 1 & 2.5 & na & na \\
\hline
\end{tabular}

*na denotes not applied

When asked about their opinion of other people's drinking behaviour with regard to exercise, $17.5 \%, 27.5 \%$ and $45.0 \%$ of the participants said the people attending their class are always drink before, during and after exercising, respectively. Meanwhile, $77.5 \%, 72.5 \%$ and $52.5 \%$ of the participants believed that the people around them only sometimes drink before, during and after exercise, respectively. Approximately $5.0 \%$ and $2.5 \%$ of the participants said that they noticed people around them never had a drink before and after exercise. Overall, 72.5\% of the participants believed that other people do not drink the right amount for exercise, meanwhile $27.5 \%$ agreed that those people drink sufficiently. When asked how the participants decide when to drink during exercise and in general during the day, the response 
"feel thirsty" tops the list that lead them to drink both during exercise $(32.5 \%)$ and in general during the day (30.0\%) (Table 4).

Table 3. Participants' preferred drink before, during and after exercise and generally during the day $(n=40)$.

\begin{tabular}{|c|c|c|c|c|c|c|c|c|}
\hline \multirow[t]{2}{*}{ Types of drink } & \multicolumn{2}{|c|}{$\begin{array}{c}\text { Before } \\
\text { exercise }\end{array}$} & \multicolumn{2}{|c|}{$\begin{array}{l}\text { During } \\
\text { exercise }\end{array}$} & \multicolumn{2}{|c|}{$\begin{array}{c}\text { After } \\
\text { exercise }\end{array}$} & \multicolumn{2}{|c|}{ General } \\
\hline & $\mathbf{n}$ & $\%$ & $\mathbf{n}$ & $\%$ & $\mathbf{n}$ & $\%$ & $\mathbf{n}$ & $\%$ \\
\hline Water & 30 & 75.0 & 29 & 72.5 & 24 & 60.0 & 30 & 75.0 \\
\hline Squash/cordial & 3 & 7.5 & 3 & 7.5 & 2 & 5.0 & na & na \\
\hline Sports drink & 2 & 5.0 & 8 & 20.0 & 6 & 15.0 & 1 & 2.5 \\
\hline Coffee/tea & 2 & 5.0 & na & na & na & na & 6 & 15.0 \\
\hline $\begin{array}{l}\text { Carbohydrate/protein } \\
\text { mix drink }\end{array}$ & 2 & 5.0 & na & na & 6 & 15.0 & na & na \\
\hline Energy drink & 1 & 2.5 & na & na & na & na & na & na \\
\hline Fruit juice & na & na & na & na & 1 & 2.5 & 2 & 5.0 \\
\hline Skimmed milk & na & na & na & na & 1 & 2.5 & na & na \\
\hline Carbonated drink & na & na & na & na & na & na & 1 & 2.5 \\
\hline
\end{tabular}

*na denotes not applied

Table 5 shows the median scores of the participants' rating on how good they feel the drinks provide water to the body. More than half of the participants rated plain tap water $(60.0 \%)$ and plain bottled mineral water $(70.0 \%)$ as excellent source of water for human body. In contrast, colas or lemonade and chocolate drinks were rated as a poor source of water for human body by the respective $50.0 \%$ and $55.0 \%$ of the participants. With regards to an item asking participants to list any potential problems that may arise if we have too little water in our diet, the majority of responses given by the participants were "poor bowel movement or constipation" (18.2\%), followed by "fatigue" (14.1\%), "headache" (13.1\%) and so forth. 
Table 4. Participants' responses to the question "how do you decide when to drink?" during exercise and in general $(n=40)$.

\begin{tabular}{lcccc}
\hline How do you decide when to drink? & During exercise & \multicolumn{2}{c}{ In general } \\
& n & \% & n & \% \\
\hline 1. Feel thirsty & & & & \\
2. Between sets and reps/ regular interval & 13 & 32.5 & 12 & 30.0 \\
3. Habitual/ time increment & 12 & 30.0 & na & na \\
4. Conscious of hydration/drink before getting thirsty & 3 & 7.5 & 1 & 2.5 \\
5. Feel dry mouth & 3 & 7.5 & 5 & 12.5 \\
6. Intuitive & 2 & 5.0 & 2 & 5.0 \\
7. When get opportunity/time break & 2 & 5.0 & 4 & 10.0 \\
8. Drink regularly or sip continuously & 2 & 5.0 & 2 & 5.0 \\
9. If sweating a lot & 1 & 2.5 & 12 & 30.0 \\
10. When I stop exercising & 1 & 2.5 & na & na \\
11. Watch urine colour & 1 & 2.5 & na & na \\
\hline
\end{tabular}

*na denotes not applied

Conversely, in response to an item asking the participants to list any potential problems that may arise if we have too much water in our diet, the most popular responses given by the participants were "flush out mineral/salt dilution/hyponatremia" (24.2\%), followed by "increase urination/toilet visit or water incontinence" (21.2\%), "feel bloated" (18.2\%) and others $(36.4 \%)$. 
Table 5. Median rating score on types of drink that provide water to the body, frequency and percentage of participants for the median score $(n=40)$.

\begin{tabular}{llcc}
\hline \multicolumn{1}{c}{ Types of drink } & Median & Frequency & Percentage \\
& (range) & (n) & (\%) \\
\hline 1. Plain tap water & & & \\
2. Plain bottled mineral water & $5(1-5)$ & 24 & 60.0 \\
3. Sparkling water & $5(1-5)$ & 28 & 70.0 \\
4. Flavoured water & $3(1-5)$ & 12 & 30.0 \\
5. Fruit juices & $4(1-5)$ & 14 & 35.0 \\
6. Vegetable juices & $3(1-4)$ & 17 & 42.5 \\
7. Milk & $3(1-5)$ & 15 & 37.5 \\
8. Colas/lemonades etc & $3(1-5)$ & 18 & 45.0 \\
9. Sports drinks & $1(1-5)$ & 20 & 50.0 \\
10. Energy drinks & $4(1-5)$ & 17 & 42.5 \\
11. Tea & $3(2-5)$ & 15 & 37.5 \\
12. Coffee & $3(2-5)$ & 17 & 42.5 \\
13. Chocolate & $2(1-5)$ & 19 & 47.5 \\
14. Soup & $1(1-5)$ & 22 & 55.0 \\
\hline & $2(1-5)$ & 14 & 35.0 \\
\hline
\end{tabular}

\section{DISCUSSION}

The main findings of the study showed that the participants had some knowledge but also some misunderstanding with respect to hydration and fluid intake. Most participants $(>50.0 \%)$ in the present study believed that they should drink before, during and after exercise to stay hydrated and to replace fluid loss. This result was similar to the findings of the survey conducted by Decher et al. [12] on hydration status, knowledge and behaviour in youths at summer sports camps in Connecticut and Pennsylvania. On scale 1 (never) to 10 (always), the adolescent participants agreed it is important to drink to stay hydrated before $(9.7 \pm 0.5)$, during $(9.8 \pm 0.5)$ and after $(9.1 \pm 1.3)$ practices and games. Despite the suggestion made by American College of Sports Medicine [13] and National Athletic Trainers' Association [14] 
on sports drink consumption during high intensity exercise for more than $1 \mathrm{~h}$ and less intense exercise sustained for longer period, water was regarded as the best drink by these individuals and was the most preferred beverage to be consumed by the participants during exercise. This result is supported by the work of Schroder et al. [15] who conducted a survey on dietary habits and fluid intake of the elite Spanish basketball players and observed that water was the preferred beverage consumed by the participants during training (92\%) and competition $(88 \%)$. If people regularly exercise for more than $1 \mathrm{~h}$ at high intensity or less intense but sustained for a longer period, sports drinks may be a better option for fluid and fuel replacement during exercise because sodium and carbohydrate contents help to increase physiological drive to drink to replace sweat losses and to maintain blood glucose level, respectively [13]. This result from the present study was comparable to the previous works reported by Felder et al. [7] and Nichols et al. [8], whereby the athletes showed little understanding about the positive effect of carbohydrate electrolyte drinks in maintaining proper hydration status and exercise performance.

Surprisingly, the present study also revealed that most of the participants believed that plain water is the excellent source of fluid for human body, whereas cola and chocolate drinks as poor sources of hydration. However, some recent evidence suggest that other beverages such as orange juice, coffee $[5,16,17,18]$ and black tea $[6]$ are as good as plain water to hydrate the body. Thus, the participants in our study may need to reconsider their view about other beverages besides plain water to rehydrate. Furthermore, the results show that "feels thirsty" was the main trigger for drinking during exercise and in general during the day. Under resting conditions, thirst is adequate to stimulate fluid intake in order to prevent hypohydration but that is not hold true during exercise [19]. This concern results in ACSM fluid replacement guideline which recommends that during exercise, people should drink fluid to limit body mass loss to less than $2 \%$ body mass to maintain the exercise performance [13]. However, other investigators have challenged this view and recommend that exercising individuals should only drink as dictated by thirst because drinking ad libitum results in similar performance outcome as drinking to replace the body mass loss during exercise [20]. Thus, further work in the area of hydration, thirst and fluid intake is warranted to ascertain the view. The present study also investigated the issue of health concerns regarding under or over 
consumption of water. Among the popular responses given by the participants regarding the effect of little water consumption on health were "constipation", "fatigue" and "headache". The role of water together with fibre in maintaining bowel function is well recognized [10]. Lack of fluid during exercise may lead to dehydration, which then increases core body temperature and also disturbs electrolyte balance and eventually fatigue will occur. Headache is also often attributed to water deprivation, but the view remains inconclusive. Work conducted by Spigt et al. [21] showed that there was no significant difference found in terms of experiencing headache between participants who increased their fluid intake compared to those who did not. On the other hand, Shirreffs et al. [22] who conducted the study on the effects of fluid restriction on hydration status and subjective feelings in adult males and females showed that the participants reported to have significantly greater feeling of headache at 24 and $37 \mathrm{~h}$ of fluid restriction trial compared to euhydrated trial.

For the question on the effect of too much water consumption on the human body, the responses "flush out of mineral/hyponatraemia" and "increased urination" were among the most popular answers given by the participants. Overhydration is often related to hyponatraemia, a condition of diluted sodium caused by excessive water intake over a short period of time, which has been reported in a small number of recreational and endurance-exercising individuals [23, 24]. Increased urination is the result of decreased antidiuretic hormone secretion in order to maintain normal body fluid volume. From the results of the present study, it could be concluded that most participants were knowledgeable and aware about the issue of general health and amount of water consumption. This study also revealed that $80.0 \%$ of the participants reported to be aware of their hydration status based on their urine colour and their subjective feelings such as "feel thirsty" and "headache". According to Armstrong et al. [25], urine colour may be used as a reliable tool to assess hydration status when other laboratory-based indices such as urine specific gravity and urine osmolality are unavailable. However the use of subjective feelings to measure hydration status still lacks strength of evidence [26], but has since been further investigated [27].

Furthermore, the results show that plain tap water was reported to be consumed the most (1.5 $\pm 1.2 \mathrm{~L}$ ) during an average day compared to other beverages which parallel to the participants' belief that water is the most hydrating (Table 2) and most preferred beverage during exercise 
and in general during the day (Table 3). This finding was similar with the Malaysian Adult Nutrition Survey which showed that $90.3 \%$ adults consumed plain water daily with the mean intake of $1688 \mathrm{ml} /$ day [28]. However, Guelinckx et al. [29] conducted the study on the water and other beverage consumption in 13 different countries revealed that in UK, Poland, Germany and Japan, water became the second largest contributor to total fluid intake after hot beverages.

Concerning the participants' opinion on other people hydration habits, most of the participants believed that people around them did not always drink during exercise and did not drink sufficiently for exercise. At present, no published studies that the investigator is aware of are available to either support or refute this view. It is difficult to determine the quantity that is deemed a sufficient amount to drink for exercising individuals because it depends on many factors such as duration and types of exercise and environmental conditions. However, established guidelines of fluid replacement for exercise by ACSM recommend that before exercise, exercising individuals are to drink slowly approximately $5-7 \mathrm{ml} \mathrm{kg}^{-1}$ per body weight of fluid $4 \mathrm{~h}$, only if they have not consumed sufficient beverages with meals and there has been insufficient recovery period since the last exercise session, to drink fluid to limit body mass loss to less than $2 \%$ body mass during exercise and to consume normal meals and beverages after exercise in order to restore euhydration [13].

Misconception in some aspects of hydration may probably be due to widely dissemination of information which has not backed up by scientific evidence. Previous data have shown that athletes receive most of the information from sport magazines [30], while coaches from both magazines and professional conferences [31]. While professional conferences may provide more sound knowledge about hydration, magazines may present some misinformation on hydration based on questionable research. Therefore, investigation into the types of sources of information obtained and the level of knowledge may be appropriate. Furthermore, the results of this study only reflect the perception of the certified fitness professionals who are known to have a basic knowledge of hydration. Therefore, certain aspects of hydration and fluid intake which they show substantial amount of correct knowledge is expected. This study could be extended to see whether general population such as sedentary or recreationally active population would exhibit the similar or different perception regarding hydration and fluid 
intake.

\section{CONCLUSION}

In general, the fitness professionals in this study demonstrated many acceptable perceptions that are in line with scientific evidence in the area of hydration, thirst and fluid intake. However, the present study also identifies the need for fitness professionals to accurately pick information based on sound evidence regarding their perspectives on hydration and fluid intake habits.

\section{ACKNOWLEDGEMENTS}

The authors were grateful for the full cooperation from the research participants and the Ministry of Higher Education Malaysia for financial support.

\section{REFERENCES}

[1] Valtin H. "Drink at least eight glasses of water a day." Really? Is there scientific evidence for “8 x 8”? American Journal of Physiology 2002, 283: R993-R1004.

[2] Passmore A. P, Kondowe G. P, and Johnston G. D. Renal and cardiovascular effects of caffeine: a dose-response study. Clinical Science 1987, 72: 749 - 756.

[3] Neuhauser-Berthold B. S, Verwied S. C, and Luhrmann P. M. Coffee consumption and total body water homeostasis as measured by fluid balance and bioelectrical impedance analysis. Annals of Nutrition Metabolism 1997, 41: 29 - 36 .

[4] Maughan R. J, and Griffin J. Caffeine ingestion and fluid balance: a review. Journal of Human Nutrition and Dietetics 2003, 16: 411-420.

[5] Grandjean A. C, Reimers K. J, Haven M. C, and Curtis G. L. The effect on hydration of two diets, one with and one without plain water. Journal of American College of Nutrition 2003, 22(2): 165-173.

[6] Ruxton C. H, and Hart V. A. Black tea is not significantly different from water in the maintenance of normal hydration in human subjects: results from a randomised controlled trial. British Journal of Nutrition 2011, 106(4): 588-595.

[7] Felder J. M, Burke L. M, Lowdon B. J, Cameron-Smith D, and Collier G. R. Nutritional 
practices of elite female surfers during training and competition. International Journal of Sport Nutrition 1998, 8: 36-48.

[8] Nichols P. E, Jonnalagadda S. S, Rosenbloom C. A, and Trinkaus M. Knowledge, attitude and behaviours regarding hydration and fluid replacement of collegiate athletes. International Journal of Sport Nutrition and Exercise Metabolism 2005, 15: 515-527.

[9] Soo K, and Naughton G. The hydration profile of female cricket players during competition. International Journal of Sport Nutrition and Exercise Metabolism 2007, 17: 14-26.

[10] Popkin B. M, D’Anci K. E, and Rosenberg I. H. Water, hydration and health. Nutrition Reviews 2010, 68(8): 439-458. doi:10.1111/j.1753-4887.2010.00304.x.

[11] Armstrong L. E. Challenges of linking chronic dehydration and fluid consumption to health outcomes. Nutrition Reviews 2012, 70 (Suppl 2): S121-7, doi: 10.1111/j.1753-4887.2012.00539.x.

[12] Decher N. R, Casa D. J, Yeargin S. W, Ganio M. S, Levreault M. L, Dann C. L, et al. Hydration status, knowledge and behaviour in youths at summer sports camps. International Journal of Sports Physiology and Performance 2008, 3: 262-278.

[13] Sawka M. N, Burke L. M, Eichner E. R, Maughan R. J, Montain S. J, and Stachenfeld N. American College of Sport Medicine Position Stand: Exercise and fluid replacement. Medicine and Science in Sports and Exercise 2007, 39(2): 377-390.

[14] Casa D. J, Armstrong L. E, Hillman S. K, Montain S. J, Reiff R. V, Rich B. S. E, et al. National Athletic Trainers' Association position statement: Fluid replacement for athletes. Journal of Athletic Training 2000, 25: 212-224.

[15] Schroder H, Navarro E, Mora J, Seco J, Torregrosa J. M, and Tramullas A. Dietary habits and fluid intake of a group of elite Spanish basketball players: a need for professional advice? European Journal of Sport Science 2004, 4(2): 1-15.

[16] Killer S. C, Blannin A. K, and Jeukendrup A. E. No evidence of dehydration with moderate daily coffee intake: a counterbalanced cross-over study in a free-living population. PLoS ONE 2014), 9(1): e84154. doi:10.1371/journal.pone.0084154

[17] Tucker M. A, Ganio M. S, Adams J. D, Brown L. A, Ridings C. B, Burchfield J. M, et al. Hydration status over $24-\mathrm{H}$ is not affected by ingested beverage composition. Journal of 
American College of Nutrition 2015, 34(4):318-27. doi: 10.1080/07315724.2014.933684. Epub 2015 Mar 19.

[18] Seal A. D, Bardis C. N, Gavrieli A, Grigorakis P, Adams J. D, Arnaoutis G, et al. Coffee with high but not low caffeine content augments fluid and electrolyte excretion at rest Frontiers in Nutrition 2017,| doi.org/10.3389/fnut.2017.00040

[19] Passe D. H, Horn M, Stofan J, Horswill C, and Murray R. Voluntary dehydration in runners despite favourable conditions for fluid intake. International Journal of Sport Nutrition and Exercise Metabolism 2007, 17: 244-295.

[20] Noakes T. D. Drinking guidelines for exercise: what evidence is there that athletes should drink "as much as tolerable", "to replace the weight loss during exercise" or "ad libitum"? Journal of Sport Sciences 2007, 25(7): 781-796.

[21] Spigt M. G, Kujiper E. C, Schayck C. P, Troost J, Knipschild P. G, Linssen V. M, et al. Increasing the daily water intake for the prophylactic treatment of headache. A pilot trial. European Journal of Neurology 2005, 12: 715-718.

[22] Shirreffs S. M, Merson S. J, Fraser S. M, and Archer D. T. The effects of fluid restriction on hydration status and subjective feelings in man. British Journal of Nutrition 2004, 91: 951-958.

[23] Noakes T. D, and Speedy D. B. Case proven: exercise associated hyponatraemia is due to overdrinking. So why did it take 20 years before the original evidence was accepted? British Journal of Sports Medicine 2006, 40(7): 567-572.

[24] Hew-Butler T, Loi V, Antonello Pani A, and Rosner M. H. Exercise-Associated Hyponatremia: 2017 Update. Frontiers in Medicine 2017, doi.org/10.3389/fmed.2017.00021.

[25] Armstrong L. E, Maresh C. M, Castellani J. W, Bergeron M. F, Kenefick R. W, LaGasse K. E, et al. Urinary indices of hydration status. International Journal of Sport Nutrition 1994, 4: $265-279$.

[26] Armstrong L. E. Assessing hydration status: the elusive gold standard. Journal of American College of Nutrition 2007, 26 (5): 575S-584S.

[27] Jusoh N, and Shirreffs S. M. Thirst as a marker of hydration status? British Journal of Sports Medicine 2009, 43(E2): 7.doi:10.1136/bjsm.2009.066886x 
[28] Institute for Public Health (IPH). National Health and Morbidity Survey 2014: Malaysian Adult Nutrition Survey (MANS) Vol. II : Survey Findings. Kuala Lumpur, 2014.

[29] Guelinckx I, Ferreira-Pego C, Moreno L. A, Kavouras S. A, Gandy J, Martinez H, et al. Intake of water and different beverages in adults across 13 countries. European Journal of Nutrition 2015, 54 Suppl (2):S45-S55. doi: 10.1007/s00394-015-0952-8.

[30] Jacobson B. H, Sobonya C, and Ransone J. Nutrition practices and knowledge of college varsity athletes: a follow-up. Journal of Strength and Conditioning Research 2001, 15(1): 63-68.

[31] Geijer J. R, Pitney W. A, and Brandenburg J. Fluid replacement knowledge and sources of hydration information among Illinois high school athletic coaches. The Internet Journal of Allied Health Science Practice 2009, 7(3): 1-6.

\section{How to cite this article:}

Jusoh N, and Shirreffs S M. Fitness professionals' knowledge and perceptions on hydration and fluid intake: a preliminary study. J. Fundam. Appl. Sci., 2017, 9(6S), 1024-1040. 